\title{
LA CONTABILIDAD COMO HERRAMIENTA PARA FRENAR LA PLANIFICACIÓN FISCAL AGRESIVA
}

\author{
Francisco Jesús MarTínez JiMÉNEZ \\ Universidad de Jaén \\ E-mail: fmartine@ujaen.es
}

\begin{abstract}
RESUMEN: Este artículo se enmarca en el ahorro impositivo que forma parte del objetivo de rentabilidad de las empresas. Por tanto, el objetivo de este trabajo es analizar la incidencia de la planificación fiscal en el proceso de creación de normas contables y su convergencia con el ordenamiento tributario. Para ello, desde el punto de vista metodológico, debemos analizar los distintos avances normativos en contabilidad, así como en el Derecho tributario y la incidencia de la globalización en las operaciones empresariales. En definitiva, se busca evidenciar que una armonización fiscal será la única herramienta útil para la eliminación de los efectos negativos que tiene, en la toma de decisiones de las empresas, la estructuración de una planificación fiscal agresiva.
\end{abstract}

Palabras clave: Contabilidad; planificación fiscal agresiva; impuesto sobre sociedades.

\begin{abstract}
The framework of this paper is fact that tax savings are part of the profitability objective of companies. Therefore, the aim of this work is to analyze the incidence of the fiscal planning in the process of creation of accounting regulations and its convergence with the tax system. For this purpose, from a methodological point of wiew, we must analyse the various regulatory developments in accounting, as well as in tax law and the impact of globalization on business operations. In conclusion, the aim is to show that tax harmonization will be the only useful tool for eliminating the negative effects that the structuring of aggressive tax planning has on the decisionmaking of companies.
\end{abstract}

Keywords: Accounting; Aggressive tax planning; Corporate Tax.

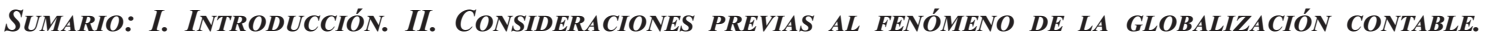

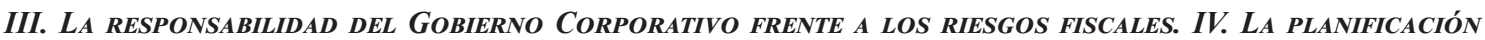


FiSCAL COMO eSTRATEGIA EMPRESARIAL 4.1. Variables de la planificación fiscal. 4.2. Legitimación de la planificación

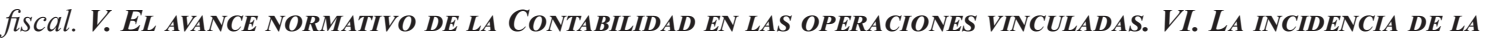
CONTABILIDAD EN LA FISCALIDAD. VII. CONCLUSIONES. VIII. BIBLIOGRAFÍA.

\section{INTRODUCCIÓN}

Este trabajo intentará establecer unas ideas básicas sobre la homogeneización que ha sufrido las normas contables a nivel global. Posteriormente, creemos que sería recomendable enlazar las recomendaciones de la auditoría contable con los riesgos fiscales, desde la perspectiva de la responsabilidad del Gobierno Corporativo. Esto nos hará ver que la planificación empresarial puede pasar por estructurar operaciones que disminuyan la carga fiscal legítimamente, es decir, deberemos poner de manifiesto la legitimación de la planificación fiscal dentro de aquellas tomas de decisiones empresariales. En cierta manera, esta planificación fiscal supondrá abordar las operaciones vinculadas y como la normativa contable ha intentado justificar su existencia. Terminando cómo la contabilidad ha incidido en el desarrollo normativo tributario y poder expresar nuestras conclusiones.

Por lo expuesto, debemos poner de manifiesto que los principios de justicia tributaria persiguen el establecimiento de un sistema de imposición aparejado con el lugar donde se generen los beneficios. En este sentido, la fiscalidad internacional busca impedir que las empresas multinacionales eviten, de forma artificial, ser sometidas a imposición en los distintos ordenamientos tributarios en los que desarrollen sus actividades económicas. En el mismo camino se encuentra el avance normativo de la contabilidad acerca de aportar información útil sobre los riesgos fiscales a los que son sometidas las sociedades en el ámbito internacional.

Por ende, cuando hablamos de las estrategias empresariales, desde la perspectiva de la planificación fiscal, veremos cómo éstas intentan aprovechar las diferencias existentes entre los distintos sistemas tributarios. Es decir, observamos que multitud de empresas con presencia internacional se benefician de situaciones jurídicas que se generan entre la jurisdicción tributaria donde se origina la renta y la jurisdicción receptora de la misma. Estas situaciones generan una gran preocupación cada vez más acuciante en los gobiernos nacionales en combatir la evasión fiscal, el fraude o la planificación fiscal agresiva.

Lo anterior origina, desde la perspectiva de la UE, el establecimiento de situaciones jurídico-económicas que garanticen una mayor seguridad jurídica para los agentes económicos. Dichas situaciones van a generar efectos negativos a nivel de recaudación por parte de los gobiernos, puesto que afectará a la capacidad de los Estados de exigir la tributación a los contribuyentes que desarrollen una actividad económica en su territorio. Dicho de otro modo, aquella limitará de forma sustantiva el poder de éstos en intervenir en el mercado.

Cuando nos referimos a la intervención en el mercado hablamos de la capacidad del Estado en exigir ciertos comportamientos a sus agentes o limitar el mercado -ya sea mediante el establecimiento de barreras de entrada o eliminándolas- de manera que se pueda garantizar la redistribución de la riqueza. Con ello queremos decir que este fenómeno desencadena transformaciones de las características esenciales de los sistemas normativos, generando cambios en los principios que constituyen tales sistemas. 
Sin embargo, cuando se avanza en la creación normativa tributaria sobre la imposición de los beneficios empresariales para hacer frente a los distintos tipos de abuso, olvidamos que estas ganancias se sustentan en la normativa contable y, por tanto, los avances en materia tributaria serían más eficientes si van acompañados de unas mejoras normativas acerca de la información cantable que deben publicar las empresas. Es menester reconocer que existen progresos paulatinos sobre aspectos de la divulgación financiera y no financiera, concretamente cuando nos referimos a los métodos de control y de supervisión de la auditoria.

Otra circunstancia a señalar es la homogeneización de los métodos de producción, que imposibilita la determinación de los costes de las empresas. Las distintas operaciones comerciales que realizan las empresas provocan que exista una compleja situación para identificar donde se genera el coste o en qué departamento. O lo que es lo mismo, dichas entidades en su afán de buscar la manera de ahorrar costes y de mejorar la eficiencia productiva, utilizarán métodos de producción en cadena radicada en diferentes Estados. Adicionalmente, esta problemática se acentuará con las operaciones de comercio electrónico -las llamadas global trading operations - que dificultarán dicha determinación. A ello hay que sumar el amplio margen de maniobra que tienen los agentes integrantes de grupos de empresas multinacionales para transferir costes de un lugar a otro del mundo.

La organización de este artículo es la siguiente. Después de esta breve introducción, en la Sección 2, se presentan unas consideraciones generales sobre cómo la globalización ha afectado a la doctrina contable. Otro aspecto a analizar para el desarrollo del presente trabajo se encuentra en el gobierno corporativo de la empresa que se desarrolla en la Sección 3. A continuación, en la Sección 4, abordaremos las variables y la legitimidad de la planificación fiscal en las operaciones intragrupo. En este sentido, en la Sección 5, se analizará el avance de la normativa contable en las operaciones vinculadas. Esto nos llevará a realizar un estudio de la incidencia de la contabilidad en la materia tributaria en la Sección 6. Y será en la Sección 7 donde plantearemos nuestras conclusiones.

\section{CONSIDERACIONES PREVIAS AL FENÓMENO DE LA GLOBALIZACIÓN CONTABLE}

La globalización ha ido generando unos efectos sobre el desarrollo empresarial de los agentes económicos con base en las siguientes circunstancias: 1) por la internacionalización del capital; 2) el aumento del comercio internacional, cobrando importancia los derechos de propiedad intelectual debido a que dicho comercio está compuesto de bienes intangibles; 3) el progreso en la ciencia tecnológica, ya que permite la circulación de masas grandes de flujo monetario, generando, a su vez, innovación; y 4) el poder fijado en la banca internacional y los organismos globales.

Estas circunstancias han provocado que los Estados hayan preferido adaptar la normativa contable a los intereses de los propios mercados, tanto financieros como de capitales. La consecuencia de ello es que éstos establecerán las reglas necesarias para la participación en el mercado por los agentes económicos. Todo ello ha propiciado el fenómeno de la "globalización contable", a través de organismos emisores de normas 
contables a nivel internacional que, según García Novoa, «han ido creando estructuras orgánicas que dinamizan la puesta en vigencia de la propuesta estandarizadora» ${ }^{1}$.

Una estandarización de las normas contables supone facilitar los intereses particulares de las corporaciones multinacionales. En otras palabras, vemos que los ordenamientos jurídicos han adaptado sus normativas internas contables en aras de garantizar una seguridad jurídica, de forma que, aquellas corporaciones tengan menos trabas a la hora de realizar inversiones en un lugar u otro del mundo. En palabras de Stiglitz, «la globalización no ha conseguido reducir la pobreza, pero tampoco garantizar la estabilidad $»^{2}$.

La globalización contable supone una suerte de resignación «en los diferentes procesos organizacionales; modificaciones en la medición, reconocimiento y revelación de los diferentes hechos; modificaciones en la manera de negociar y establecer términos contractuales; adquisiciones o adecuaciones de plataformas tecnológicas e informáticas; cambios en la forma de ejercer el control o evaluación de los hechos; efectos sobre la educación contable, puesto que, ésta deberá atender los retos impuestos por los nuevos marcos normativos y modificaciones en la relación fiscalidad-contabilidad y, con ello, en la forma de trasladar la información contable-financiera a las administraciones tributarias» ${ }^{3}$.

Desde el punto de vista fiscal, también se observan una serie de cambios, tanto en el Derecho tributario como en los sistemas tributarios nacionales, modificando los sistemas de generación de riqueza, de manera que un Estado persigue la atracción de capital a su territorio en forma de nuevas inversiones o de nuevos contribuyentes.

Dicho de otro modo, la globalización supone un cambio en las políticas fiscales, convirtiendo los ordenamientos tributarios en regímenes fiscales favorables o, incluso, en zonas de baja tributación. Esta política afecta al resto de Estados que prefieren mantener una elevada presión fiscal sobre sus contribuyentes, a través de acciones legislativas que intenten paliar la posible disminución de los ingresos públicos. Tanzi ya destacaba que al final todos los Estados establecerán una legislación tributaria que se acerque a las tendencias del mercado internacional, a través de tipos impositivos más bajos, manteniendo la transparencia y la legalidad exigidos en los estándares internacionales; pero permitiéndoles seguir recaudando los ingresos necesarios que permitan alcanzar los objetivos del Estado ${ }^{4}$. Aunque nosotros creemos que esta bajada de presión fiscal puede suponer una reducción de la recaudación e imposibilitar alcanzar las pretensiones de un Estado social y democrático de Derecho.

En otras palabras, la globalización, desde la perspectiva fiscal, hará que los principios clásicos del Derecho tributario vayan perdiendo importancia o que pueden ser un gran foco de conflictos. En este sentido, para Tanzi, un sistema tributario empleará su potestad tributaria sobre aquella riqueza generada dentro de los límites de su territorio,

1 GARCÍA NOVOA, C. "El derecho tributario a las puertas del Siglo XXI. Retos de futuro". Mundo fiscal, Vol.1, 2009, pág 19.

2 STIGLITZ, J. El malestar en la globalización. Punto de lectura, Madrid, 2002, pág. 40.

3 MARTÍNEZ JIMÉNEZ, F.J. "La incidencia contable en la fiscalidad: ¿Hacía una reducción de la carga tributaria?, en la obra colectiva V.V.A.A. Actas del XIX Encuentro Internacional AECA-Guarda 2020, AECA, Madrid, 2020, pág 11.

4 TANZI, V. "La globalización y las acciones de las termitas fiscales", Finanzas y Desarrollo, Fondo Monetario Internacional, 2001, pág. 37. 
circunstancia que limita el poder tributario de un Estado ante la situación de extrema movilidad de las rentas, perdiendo efectividad recaudatoria con el aumento de la globalización ${ }^{5}$.

En cierta manera, desde hace años se considera que globalización genera unos efectos negativos en el Derecho tributario en su conjunto, pero, en realidad, la reacción que ha tenido dicho Derecho es internacionalizarse frente de los Derechos intrínsecos de cada ordenamiento. Según Cruz Padial el aumento de las influencias que recibe del exterior el Derecho tributario, por el hecho de querer seguir practicando un gravamen a las rentas de fuera de su territorio, han ido generando nuevas fuentes y principios para sustentar la producción normativa en materia tributaria ${ }^{6}$.

La globalización ha supuesto la creación de grandes contribuyentes internacionales o corporaciones empresariales con elevados ingresos -que en ocasiones suponen el PIB de muchos Estados del mundo-, que buscan localizar sus actividades económicas o dónde radicar sus inversiones financieras. En base a lo anterior, estos contribuyentes tendrán en cuenta la posibilidad de influir en la política fiscal de los Estados con el objetivo de relajar la presión fiscal sobre sus rentas de capital a la hora de decidir donde instalarse ${ }^{7}$.

Para García Novoa este tipo de política fiscal por parte de determinados Estados puede generar una competencia fiscal perniciosa, que a su vez provoca una erosión de bases imponibles en los Estados de la fuente y efectos nocivos en el Estado de residencia al alterar el sistema tributario interno, generando disparidad entre los contribuyentes ${ }^{8}$.

Aunque destacamos la parte negativa de la globalización, también tiene efectos positivos, ya que homogeneiza conductas y actividades a nivel internacional. Esto nos hace pensar que en el futuro existirá una convergencia entre las distintas jurisdicciones que neutralicen la competencia fiscal perniciosa. Sin embargo, estaremos más cerca de encontrarnos ante la situación del dilema del prisionero recogido en la teoría de juegos de Nash, donde al final los perjudicados son los propios sistemas tributarios que ven limitado su objetivo de mantenimiento del Estado del bienestar'.

5 TANZI, V. "Globalization, Tax Competition and the Future of Tax Systems", Documento de Trabajo WP/96/141, Fondo Monetario Internacional, 1996, pág. 5.

6 CRUZ PADIAL, I. "Globalización Económica: Sinónimo de desnaturalización tributaria”, Crónica Tributaria, núm. 109, 2003, pág. 59

7 El autor CRUZ PADIAL denomina este fenómeno como la «desfiscalización de la imposición sobre las rentas de capital», es decir, los grandes contribuyentes buscarán poder influir en las Administraciones tributarias con el objetivo de tener una imposición baja o nula, mediante acuerdos con estas Administraciones -los llamados Tax rulings-. En definitiva, supone olvidar los principios clásicos y constitucionales, a cambio de aumentar la competitividad de la economía nacional o la eficiencia económica, basándose en la potestad tributaria del Estado, generando una competencia fiscal con el resto de países. (op. cit., págs. 59 y 60).

8 Se entiende como Estado de la fuente aquella jurisdicción tributaria donde se originan las rentas obtenidas por un contribuyente residente en otro Estado. En el Derecho internacional tributario, se diferencia entre el Estado de residencia y el Estado de la fuente, para determinar que ordenamiento fiscal tiene la potestad para gravar las rentas originadas. Vid. GARCÍA NOVOA, C: "El actual contexto internacional y el principio de residencia en las rentas de actividades empresariales", Crónica Tributaria, núm. 165, 2017, págs. 33-54.

9 NASH, J.F. (1950): "Equilibrium Points in n-Person Games," Proceedings of the National Academy of Sciences, Vol. 36, 1950, págs. 48 y 49. 
Lo cierto es que hay Estados que exprimen los efectos negativos de la globalización, mediante una política fiscal donde se mantiene una presión fiscal elevada sobre determinados contribuyentes y reduciéndolos al resto -conocida ésta como «dual income tax»-. Es decir, han decidido establecer un gravamen reducido y proporcional sobre las rentas del capital, mientras se mantiene o eleva la presión fiscal sobre las rentas del trabajo.

Se puede pensar que esta política fiscal se trata de un instrumento neutralizador de la competencia fiscal perniciosa. Pero, desde nuestro punto de vista, dicha herramienta no respeta los principios de justicia tributaria del Derecho tributario, ya que no se aplica de forma correcta ni el principio de igualdad o el principio de capacidad económica y, además, limita la actuación del Estado en su función de generar una redistribución de la renta.

Todo lo anterior genera grandes distorsiones, especialmente en el Impuesto sobre Sociedades, ya que, al establecer un tipo impositivo ante una base imponible estática, posibilita una planificación que, a través de operaciones intragrupo, merme dicha base y, por tanto, reduzca la tributación de los contribuyentes. A lo que hay que sumar la competencia fiscal entre Estados con el fin de atraer nuevos contribuyentes a su territorio, mediante incentivos fiscales. El resultado de todo ello, es que, aunque en términos generales se haya aumentado la actividad económica y, por tanto, las bases imponibles tendrían que haber aumentado, vemos que los Estados han sufrido una disminución de los ingresos públicos provenientes de aquel impuesto.

Para Calderón Carrero el principal efecto de la globalización es la internacionalización del Derecho tributario y la generación de nuevas fuentes y principios. En este sentido, se pueden mencionar los convenios de doble imposición, el «soft law» del TJUE, los principios emanados de la OCDE, algunos preceptos de los distintos tratados de la OMC -Organización Mundial del Comercio-, el Tratado de Funcionamiento de la UE y, por último, las Directivas europeas -y con menor importancia, los Reglamentos europeos $-{ }^{10}$.

Dicho de otro modo, se está originando un cambio en los principios tributarios, esto es, establecer una menor intervención del Estado en las decisiones de los operadores económicos, una mayor transparencia de los sistemas tributarios, una reducción de los costes administrativos y de cumplimiento de las obligaciones tributarias para los contribuyentes y un impulso del principio de neutralidad que facilite la movilidad de los factores económicos y el aumento de la competitividad empresarial ${ }^{11}$.

Sin embargo, los avances normativos están olvidando los principales objetivos del Derecho tributario, que son: la redistribución de la riqueza y la constitución de un Estado del Bienestar, en pos de garantizar los principios de Libertad de Empresa y Propiedad Privada. Es decir, la lucha está entre el interés general y el interés particular, siendo por ahora el ganador, el individuo frente al conjunto de la sociedad. En consecuencia, vemos que los planteamientos que defienden una reducción de la presión fiscal para sustentar un crecimiento económico son los que se tienen en cuenta a la hora de legislar.

10 CALDERÓN CARRERO, J.M. "La incidencia de la globalización en la configuración del ordenamiento tributario del siglo XXI”, Documentos del Instituto de Estudios Fiscales, núm. 20, Madrid, 2006, pág. 14.

11 MARTÍNEZ JIMÉNEZ, F.J. "La incidencia contable en la fiscalidad: ¿Hacía una reducción de la carga tributaria?”, en la obra colectiva V.V.A.A. Actas del XIX Encuentro Internacional AECA-Guarda 2020, AECA, Madrid, 2020, pág. 13. 
En palabras de Gutiérrez Lousa y Rodríguez Ondarza, este tipo de política fiscal hará que se deba buscar una compensación recaudatoria para evitar los déficits públicos. Es decir, en la búsqueda de ampliar el número de contribuyentes se han introducido cambios en los impuestos para intentar paliar la disminución recaudatoria mediante: 1) eliminando regímenes especiales; 2) estableciendo límites a las deducciones; 3) o incrementando los tipos mínimos -a la par de que los tipos máximos han sido reducidos para mejorar los incentivos de localización- ${ }^{12}$.

En resumen, los sistemas tributarios han visto reducir sus tipos efectivos en base al principio de neutralidad. Esto ha originado sistemas más sencillos para los contribuyentes, ya que éstos tienen menores costes de administración y de cumplimiento de obligaciones tributarias. Así las cosas, vemos que hay una desfiscalización de los grandes contribuyentes en materia de fiscalidad directa, contrarrestándose mediante el aumento de la presión fiscal en los pequeños contribuyentes y en la imposición indirecta, lo que genera una transformación del «tax mix» de los ordenamientos tributarios de los distintos Estados.

Insistimos que no todo es malo en la globalización, según Collado Yurritia y Patón García, ésta ha generado importantes beneficios en la economía mundial, facilitando el aumento de la producción, del consumo y, en definitiva, de las rentas y el trabajo. Por ello, ha surgido una competencial fiscal de los sistemas tributarios, que se ha traducido en una actualización de los mismos, con el objetivo de eliminar las distorsiones que generan las deslocalizaciones de inversiones ${ }^{13}$. Aunque como hemos dicho, creemos que existirá una cierta armonización gracias a la globalización que limite, en cierta manera, la competencia fiscal perniciosa, la planificación fiscal agresiva, la erosión de las bases imponibles, el secreto bancario o el blanqueo de capitales.

\section{LA RESPONSABILIDAD DEL GOBIERNO CORPORATIVO FRENTE A LOS RIESGOS FISCALES}

En palabras de Rivero Torre, el gobierno corporativo tiene como objetivo «fortalecer la reputación corporativa de las compañías, dotándolas de mayor transparencia y de mayor control interno y también externo (auditorías), con el fin de recuperar la confianza del inversor y de protegerlo; evitando que decisiones basadas en el beneficio a corto plazo, puedan minar la salud y el valor futuro de la empresa» ${ }^{14}$.

Los estudios en Contabilidad vienen concluyendo sobre la importancia de un buen control del gobierno corporativo, a fin de evitar la discrecionalidad en la toma de decisiones de los directivos de la empresa, generada por la separación de la propiedad y el con-

12 GUTIÉRREZ LOUSA, M. y RODRÍGUEZ ONDARZA, J.A. "Las consecuencias fiscales de la globalización”, Documentos del Instituto de Estudios Fiscales, núm. 8, Madrid, 2007, págs. 7 y 8.

13 COLLADO YURRITA, M.A. y PATÓN GARCÍA, G. (2007): "Las Fuentes del Derecho Tributario Internacional", en la obra de CORDÓN EZQUERRO, T. Manual de Fiscalidad Internacional, Vol. I, $3^{\mathrm{a}}$ ed., Instituto de Estudios Fiscales, Madrid, 2007, pág. 148.

14 RIVERO TORRE, P. "Responsabilidad Social Y Gobierno Corporativo: Información Y Transparencia", Revista Asturiana de Economía, 2005, pág. 13. 
trol de la sociedad, es la llamada teoría de la agencia ${ }^{15}$. En otras palabras, los accionistas y directivos tienen intereses contrapuestos, puesto que, los primeros esperan maximizar el valor de la empresa; mientras que los segundos esperan maximizar sus propios beneficios. Ante esta situación, Rodríguez Rodríguez advierte que la contabilidad ha ido articulando mecanismos para minimizar la posible «manipulación contable, que no es otra que no informar adecuadamente de los riesgos empresariales y, por ende, disminuir la confianza de los accionistas y futuros inversores» ${ }^{16}$.

Para los autores Stolowy y Breton, «la manipulación contable está dirigida a influir sobre la percepción del riesgo empresarial que tienen los participantes de los mercados $\gg{ }^{17}$. Dicho en otro modo, tiene el objetivo de alterar los ratios financieros, como por ejemplo los beneficios por acción-desde la perspectiva de incrementar o reducir los ingresos o gastos- - y el ratio deuda/recursos propios ${ }^{18}$.

Se pretende revertir las consecuencias de estos intereses contrapuestos con las prácticas sobre buen gobierno. Es decir, éstas intentan ser un instrumento de mejora de la calidad de la información contable. Aunque lo cierto es que la literatura acerca de los efectos en el buen gobierno se han centrado en las perspectivas de los Consejos de Administración, sobre su composición, tamaño y dualidad; además de la necesidad de la existencia de un comité de auditoría o del nivel de concentración de la propiedad ${ }^{19}$.

Observándose la evolución normativa que se ha ido realizando en España se puede destacar: la Ley 27/2014, de 27 de noviembre, del Impuesto sobre Sociedades; Ley 31/2014, de 3 de diciembre, por la que se modifica la Ley de Sociedades de Capital para la mejora del gobierno corporativo; incluso, las recomendaciones que se hacen mediante el Código de Buen Gobierno de las Empresas cotizadas, así como el Código de Buenas Prácticas Tributarias.

Todo lo anterior se sustenta en la afirmación de que la planificación fiscal agresiva puede alterar las intenciones sobre la divulgación de los riesgos de la empresa, influenciada en esa manipulación contable señalada arriba. Para García Rodríguez «uno de los atractivos de los Tax Shelters es el de minimizar la carga tributaria sin necesidad de

15 Para ampliar lo comentado puede verse: JENSEN, M. C., y MECKLING, W. H. "Theory of the firm. Managerial behavior, agency costs and ownership structure", Journal of financial Economics, 3(4), 1976, págs. 305-360.; FAMA, E. F. “Agency Problems and the Theory of the Firm”, vol. 88, n. ' 2, 1980, págs. 288-307; FAMA, E. F., y JENSEN, M. C. "Separation of ownership and control”, Journal of Law and Economics, 26 (2), 1983 págs. 301-325.

16 RODRÍGUEZ RODRÍGUEZ, A.M. "La contabilidad sobre las estrategias fiscales de las operaciones del grupo ¿Un marco de información para la fiscalidad?”, Documentos del Instituto de Estudios Fiscales, Núm. 15., 2016, pág. 124.

17 STOLOWY, H., y BRETON, G. "A framework for the classification of accounts manipulations", Les cahiers de recherche, 708, Chambre de Commerce et d'industrie de Paris, 2000, pág. 2.

18 Esta teoría ha sido bastante desarrollada por autores como: ELVIRA BENITO, O., y AMAT SALAS, O. "La manipulación contable: tipología y técnicas", Partida doble, núm. 203, 2008, págs. 48-59.

19 Vid. BEASLEY, M. "An Empirical Analysis of the Relation between the Board of Director Composition and Financial Statement Fraud”, The Accounting Review, vol. 71, núm. 4, 1996, págs. 443-465; DECHOW, P.; SLOAN, R., y SWEENEY, A. "Causes and consequences of earnings misstatement: An analysis of firms subject to enforcement actions by the SEC", Contemporary Accounting Research 13 (1), 1996, págs. 1-36; y CALLAO GASTON, S.; GASCA GALÁN, M., y JARNE JARNE, J. I. “Gobierno corporativo e información contable", Revista de Contabilidad, vol. 1, 2008, págs. 133-156. 
disminuir el resultado del ejercicio. De otra manera el producto perdería una gran parte de su atractivo pues del resultado depende en alguna medida la cotización bursátil y consecuentemente la satisfacción de los accionistas, pero también las retribuciones variables del personal directivo que son quienes, en último término, deben tomar la decisión de participar en el Tax Shelter. Por eso llega a decirse en el mercado de los Tax Shelters que un producto que dañe el resultado contable no tiene viabilidad alguna» ${ }^{20}$.

\section{LA PLANIFICACIÓN FISCAL COMO ESTRATEGIA EMPRESARIAL}

\subsection{Variables de la planificación fiscal}

En nuestra opinión, podemos entender como planificación fiscal aquella estrategia llevada a cabo por los contribuyentes con el fin de conseguir una opción económica que le resulte fiscalmente más eficiente. Esta opción económica estará basada en analizar las alternativas que hubiese para realizar una operación, todas ellas igualmente legales y posibles, con el único objetivo de alcanzar la vía de minimizar lo máximo posible la carga tributaria.

En otras palabras, la planificación fiscal, la optimización fiscal o el desarrollo de economías de opción suponen alcanzar un gravamen mínimo mediante la estructuración de operaciones mercantiles. Esto origina que la planificación fiscal se haya ido convirtiendo en una variable a tener en cuenta en la toma de decisiones de la empresa, es decir, se trata de una parte importante en la estrategia empresarial global, ya que esta situación genera distintos comportamientos, y todos ellos, dirigidos a fomentar operaciones y hechos jurídicos que permitan la optimización de la carga tributaria.

El ahorro tributario que provoca la planificación fiscal se obtendrá vía reducción de la cantidad total a pagar del impuesto, por la obtención de un diferimiento del tributo al aplazar el devengo del mismo o por conseguir una disminución de la carga tributaria indirecta. Para De Arepacochaga, la planificación fiscal supone tomar diferentes estrategias $^{21}$ que alcancen una disminución del gravamen mediante una reducción de la base imponible que, a su vez, rebaje la cuota a satisfacer del impuesto. Incluso, la obtención de un diferimiento en el devengo de un tributo por el desarrollo de una operación o hecho

20 GARCÍA RODRÍGUEZ, J. M. “Tax Shelters y Fraude: Detección y Control de la Planificación Fiscal. Abusiva. Análisis de la experiencia Estadounidense”, Crónica Tributaria, núm. 140, 2011, pág., 125.

21 Generalmente, llamaremos estrategias a aquellas operaciones realizadas por multinacionales. Estas estrategias pueden incalculables, se suelen instrumentar mediante operaciones societarias donde intervienen distintas sociedades por su forma, como por ejemplo, sociedades holding -véase las sociedades BV (Besloten Vennootschap) holandesas o las holdings danesas-, sociedades con actividad financiera -en este sentido, podemos hablar de las fundaciones de Liechtenstein o los trusts-, sociedades de inversión colectiva - por ejemplo, podemos citar aquí «entidades de tenencia de valores extranjeros españolas» (ETVE), «sociedades de inversión de capital variable» (SICAV en España) «sociedades anónimas cotizadas de inversión en el mercado inmobiliario» (SOCIMI en España o las real estate investment trust (REIT) - o, incluso, por sociedades dependientes de las matrices o la propia matriz que realice una prestación de servicios al resto de entidades del grupo; que se ubicaran en unas jurisdicciones con una amplia red de CDI y un clima fiscal atractivo, para posibilitar la interacción con otras jurisdicciones. 
jurídico, con base en un marco jurídico que asegure que se está cumpliendo la ley, entendiéndose como un ahorro fiscal para las empresas ${ }^{22}$.

Lo cierto es que la planificación estará entre las conductas lícitas y legítimas, entendiéndose como ese ahorro fiscal obtenido mediante estrategias de economía de opción dentro del marco de la legalidad; y entre aquellas conductas como la elusión fiscal, conocido como el intento de que no sean gravados determinados hechos imponibles; el abuso de legislación, que supone ese desarrollo de interpretaciones de conceptos en las leyes para alcanzar un resultado fiscal no contemplado en el ordenamiento tributario; y el fraude de ley, definiéndose como aquella aplicación de exenciones o deducciones que no corresponderían sin una operación artificiosa o sin sustancia económica.

Analizando estas últimas conductas veremos que existen elementos comunes encuadrados en conductas secundum legem, pero en la sustancia contra legem. Decimos que son contra legem porque puede interpretarse que van en contra de la ley por ser ilícitas, pero no podemos verlas como "ilegitimas", ya que se tratan de actos por parte de los contribuyentes que no suponen el quebranto de ningún precepto legal, sino como una interpretación exprimida del precepto con el objetivo de beneficiar las intenciones de los contribuyentes.

Tomando de base a Stiglitz, en su obra General Theory of Tax Avoidance, identificaremos los principales elementos que tiene la planificación fiscal. Como primer elemento, el diferimiento en la imposición, definiéndose como aquella consecución de aplazar el devengo del impuesto a un futuro; el segundo elemento, el arbitraje entre tipos de gravamen distintos, entendido como una aplicación de tipos de gravamen entre individuos diferentes o al mismo contribuyente, pero en distintos devengos repartidos en el tiempo; $\mathrm{y}$, por último, el arbitraje entre operaciones sujetas a distinto trato fiscal ${ }^{23}$.

Adicionalmente, existen otras variables unidas a los elementos de la planificación fiscal, que ayudan a reducir el coste fiscal mediante la estructuración de operaciones basadas en la toma de decisiones de los contribuyentes. Estas variables son: 1) el tipo impositivo, ya que se trata del porcentaje del beneficio que obtendremos de nuestra actividad económica destinada al pago de impuestos, sin tener en cuenta exenciones o deducciones. 2) la calificación que obtengan las operaciones, lo relevante es que, frecuentemente, los contribuyentes quieran elegir la forma de realizar sus operaciones con tal de obtener una calificación que les permita una reducción en el impuesto que están obligados a soportar. 3) los incentivos recogidos en la normativa fiscal, el establecimiento de una serie de estímulos fiscales que incentiven ciertos comportamientos de los contribuyentes, auspiciados por el legislador nacional, para el desarrollo de actividades empresariales. 4) el tiempo -y la incertidumbre a él asociada-, con base en la Teoría Económica del Dinero, un desembolso tardío de un impuesto supone pagar menos impuestos en el presente y en el futuro. Otro factor de la variable del tiempo es que la cantidad a desembolsar va a depender del momento en el que se lleven a cabo los hechos jurídicos o de su duración. También podemos destacar los cambios que pueden alterar los tipos impositivos, pudiendo ser mayores

22 DE ARESPACOCHAGA, J. Planificación fiscal internacional, Marcial Pons, 2da edición, Madrid, 1998, pág. 437.

23 STIGLITZ, J. E. "The General Theory of Tax Avoidance", National Tax Journal, Columbia University Academic Commons, Vol. 38, 1985, pág. 332. 
o más bajos. Por lo tanto, todo contribuyente habrá de tener en cuenta en su planificación fiscal los efectos que genera el tiempo en su carga tributaria presente como futura, y con esta premisa el contribuyente deberá decidir cuál es el momento más oportuno para el desarrollo de sus operaciones económicas, cuando quiere recibir una renta, cuando quiere llevar a cabo una inversión o cuando quiere realizar la desinversión de la misma. 5) el espacio, siendo un factor que progresivamente ha ido alcanzando una mayor importancia dentro de las variables de la planificación fiscal. La importancia del espacio viene motivada por la incidencia del lugar donde se realice la operación económica hará depender la tributación que soporte el contribuyente, ya que las distintas jurisdicciones tributarias tendrán sistemas tributarios diferentes que motivará la ubicación de una inversión en un territorio concreto por la tributación que se vaya a tener. Esta variable afecta en los distintos ámbitos territoriales, tanto a nivel local como hasta nivel internacional. En definitiva, los contribuyentes tendrán en cuenta el espacio como incentivo para localizar sus actividades económicas, de modo que puedan cuantificar el coste fiscal entre las distintas alternativas de localización de sus inversiones. Y 6) el sujeto pasivo, entendiéndose cuando actúa como persona jurídica o persona física se tendrá un tipo de gravamen u otro.

\subsection{Legitimación de la planificación fiscal}

Se hace necesario hacer un análisis sobre los límites en los que se basa la planificación fiscal. Este análisis pretende argumentar que el uso de económicas de opción, desde la perspectiva de generar un ahorro fiscal, está dentro del marco legislativo, es decir, que dicha opción suponga una garantía para que la carga tributaria sea acorde con la capacidad económica de cada contribuyente.

A este respecto, la particularidad de las economías de opción es que se aplican, normalmente, en el ámbito internacional, por lo que, debemos analizar el Derecho tributario internacional, el Derecho Internacional tributario y el Derecho de la UE. No obstante, el estudio de este trabajo no es el análisis de dichos Derechos.

Así las cosas, centraremos la mirada en el Derecho de la UE. En este sentido, tenemos que señalar que no existe un Derecho positivo «per se» en el que basarse y, por ello, nos tendremos que basar en la jurisprudencia del TJUE (Tribunal de Justicia de la Unión Europea, antes conocido como Tribunal de Justicia de las Comunidades Europeas), como órgano armonizador en el ámbito europeo. Este desarrollo conceptual es llamado el soft law y ha sido el elemento necesario para desarrollar los conceptos jurídicos de práctica abusiva y de elusión fiscal, conceptos europeos que nos ayudarán a percibir que abusar de las Libertades de la UE, que asisten a los contribuyentes, puede originar la pérdida de los beneficios del mercado único.

Del mismo modo, habrá que analizar tanto las medidas anti-elusión contempladas en las Directivas como en las normas nacionales de los Estados miembros, que son las únicas normas que pueden restringir las Libertades de la UE de forma legítima, basándose en prevenir el abuso de dichas libertades.

En consecuencia, el soft law del TJUE ha hecho un trabajo de clarificación de cuáles son los límites de la planificación fiscal legítima, es decir, ha establecido una diferenciación entre aquellas prácticas que suponen un abuso, una elusión o un fraude de ley, mediante una armonización «en negativo» que establece un marco legal para la planifica- 
ción dentro de las fronteras de la UE. Uno de los ejemplos más claros en el desarrollo de este marco legal para la planificación fue la sentencia Halifax, donde el propio Tribunal reconoce que «el sujeto pasivo tiene derecho a elegir la estructura de su actividad de modo que limite su deuda fiscal $»^{24}$.

Siguiendo con la perspectiva del Derecho de la UE, tendremos que identificar el establecimiento de derechos y garantías, de manera directa o indirecta, sobre los contribuyentes europeos, de manera que el desarrollo jurisprudencial del TJUE ha intentado respetar tanto los derechos que generan las Libertades de la UE como las potestades tributarias de los Estados miembros. Esto se ha conseguido al desarrollar los conceptos de abuso y de elusión. Dicho de otro modo, el propio Tribunal de Luxemburgo ha intentado establecer la coexistencia de los intereses de los Estados miembros con las reflexiones que plantea la planificación fiscal respecto a los sistemas tributarios.

La propia Comisión Europea mantiene la misma opinión que hemos expuesto en su Comunicación del $2007^{25}$, donde realiza un análisis de las actuaciones armonizadoras del Tribunal de Luxemburgo. En él se enfatizaba que aún queda margen para que la jurisprudencia europea establezca criterios más claros. En otras palabras, existe margen jurídico para intentar una aplicación de los Principios generales del Derecho de la UE de forma general, en vez de realizar una interpretación sobre unas circunstancias particulares de cada caso. La propia Comisión Europea propone al TJUE que haga unas interpretaciones de los principios generales con el fin de obtener normas de aplicación general, puesto que, con sus actuales actuaciones de análisis de cada caso concreto, conlleva a no obtener fácilmente unas conclusiones implícitas en sus decisiones para hacerlas unas consecuencias generalizadas.

En aquel trabajo de la Comisión Europea plantea una serie de cuestiones sustentadas en el soft law desarrollado por el TJUE ${ }^{26}$, ofreciendo interpretaciones que no quedan del todo claras, ya que ante la falta de una armonización en la tributación directa, ¿qué pasaría ante una reacción proteccionista y sin coordinación entre los Estados miembros? ¿y ante una interpretación dispar por parte de los jueces o Administraciones tributarias de los Estados miembros que aplicasen de forma diferente los principios generales del Derecho de la UE? o incluso, ¿qué ocurriría sí en los casos de las sucesivas sentencias del TJUE, al intentar aclarar su doctrina, genera un efecto que restringe o extiende su armonización en negativo?

Como ya avanzamos en nuestra introducción de este trabajo, tras poner de manifiesto las dudas que nos surgen de la armonización en negativo realizada por el TJUE, nos hacen pensar que estamos ante una situación de inseguridad jurídica. Para asegurar el principio de seguridad jurídica, en determinados Estados miembros, su Derecho interno ofrece determinados medios, sobre todo a empresas internacionales, mediante la utilización de los tax ruling ${ }^{27}$, instrumento previo con el que pactar con la Administración aque-

24 TJCCEE, sentencia de 21 de febrero de 2006, Asunto C-255/02, Halifax, apartado 73.

25 Véase la Comunicación de la Comisión Europea del 10 octubre del 2007, COM (2007)785 final, “Aplicación de medidas contra las prácticas abusivas en el ámbito de la fiscalidad directa dentro de la UE y en relación con terceros países".

26 La propia Comisión lo interpreta como el máximo órgano armonizador del Derecho de la UE.

27 La Comisión hace referencia al Tax Ruling como «cualquier comunicación u otros instrumentos o recursos de efectos similares empleados por el Estado miembro o en su nombre en relación con la interpretación o aplicación de la legislación fiscal» (Comunicación de la Comisión Europea del 10 octubre del 2007, COM (2007)785 final). Mientras que la OCDE los define del siguiente modo: 
llas opciones lícitas, según el ordenamiento tributario vigente, que garantiza la seguridad jurídica, tanto a inversores nacionales como internacionales, en sus inversiones.

Este extremo se ha evidenciado en importantes sentencias del $\mathrm{TJUE}^{28}$, que gradualmente ha ido construyendo una perspectiva de jurisprudencia europea con un carácter imprevisible y difícilmente controlable, que aunque se ha mantenido el self-restraint del Tribunal, ha generado grandes cambios interpretativos sobre que operaciones son lícitas o cuáles se consideran abuso.

En definitiva, nuestra opinión al respecto se basa en que para que exista una carga tributaria eficiente y ajustada a Derecho llevada a cabo mediante una planificación fiscal, se debe basar en una seguridad jurídica como garantía, dentro de un marco jurídico delimitado por los principios generales de la UE asentados por el TJUE, desarrollándose dicha jurisprudencia por la doctrina de una forma clara y generalizada, que permita interpretarse de forma coherente y sin contradicciones.

Esto nos planeta una dicotomía entre la planificación fiscal y la seguridad jurídica en la interpretación y aplicación de la jurisprudencia europea con respecto a la fiscalidad, principalmente en la tributación directa, puesto que repercute en la posibilidad de obtener una indemnización del Estado para el contribuyente, aludiendo a la responsabilidad patrimonial del Estado-Legislador ${ }^{29}$, para reparar los posibles daños o pérdidas económicas ocasionadas por la infracción de Derecho de la UE por parte del Estado tras desarrollar una normativa tributaria interna. Dicho de otro modo, hay opiniones que defienden el imputar al Estado miembro la reparación de la desobediencia fiscal cometida por los contribuyentes, éstos que únicamente estaban cumpliendo la normativa fiscal nacional.

Se podría decir, que la falta de una armonización que facilite la interpretación del Derecho de la Unión posibilitaría que un ordenamiento interno pueda obstaculizar de manera ilegítima, o lo que es lo mismo decisiones lícitas y amparadas por el Derecho de la UE quedarán limitadas por los ordenamientos tributarios internos o, incluso quedasen disuadidos de adoptarse por las posibles sanciones al infringir el ordenamiento interno. Así las cosas, para el TJUE una Administración tributaria no puede negar el disfrute de la aplicación de un régimen tributario especial que limite sus Libertades europeas.

«cualquier asesoramiento, información y compromiso garantía proporcionado por una autoridad fiscal a un contribuyente o grupo de contribuyentes con respecto a su situación fiscal, en la que tiene derecho a confiar». (OECD, informe de 1998, titulado "Harmful Tax Competition: an Emerging Global Issue", OECD, Paris, 1998, págs. 20 y ss).

28 Véase, por ejemplo, la sentencia del TJCCEE de 23 de abril de 2008, Asunto C-201/05, Test Claimants in the CFC and Dividend Group Litigation, apartado 124; y la de 12 diciembre de 2006, Asunto C-446/04, Test Claimants in the FII Group Litigation, apartado 215.

29 Como bibliografía básica sobre la materia pueden consultarse los trabajos siguientes: ALONSO GARCÍA, M ${ }^{\mathrm{a}}$ C. La responsabilidad patrimonial del Estado legislador, Marcial-Pons, Madrid, 1999, págs. 137 y ss.; ALONSO GARCÍA, R. La responsabilidad de los Estados miembros por infracción del Derecho comunitario, Civitas, Madrid, 1997; y, del mismo autor, "El juez español y el Derecho comunitario", Consejo General del Poder Judicial, Madrid, 2003; COBREROS MENDAZONA, E. "Incumplimiento del Derecho comunitario y responsabilidad del Estado", Civitas, Madrid, 1994; GARCÍA DE ENTERRÍA, E. "La responsabilidad patrimonial de la Administración española por daños causados por infracción del Derecho comunitario", Gaceta Jurídica de la CEE, núm. 60, 1989; y MANGAS MARTÍN, A. y LIÑÁN NOGUERAS, D. J. Instituciones y Derecho de la Unión Europea, Tecnos, Madrid, $6^{\mathrm{a}}$ ed., 2010, págs. 404 y ss. 
Dicho esto, nuestra opinión es que el Estado miembro estaría incurriendo en una responsabilidad patrimonial legislativa. Se debe recordar que para que se dé tal responsabilidad se tienen que reunir determinados requisitos, preestablecidos por el TJUE, ya que la infracción dependerá de sí existe un eventual error en la interpretación del Derecho de la UE, y sí ese error tiene carácter inexcusable o excusable, de la norma vulnerada o del grado de claridad para identificar la vulneración y precisar que partes del Derecho de la UE se vulneran ${ }^{30}$.

Recordamos que la jurisprudencia europea ha ido marcando los límites de los obstáculos que imponen a las Libertades de la UE por parte de los Estados miembros. Éstos se basan en el interés general fiscal, en el intento de mantener unos controles fiscales eficientes, un sistema fiscal coherente o en prevenir una paulatina reducción de los ingresos públicos.

Por lo anterior, nuestra tesis es que, ante la falta de armonización en la imposición directa, los Estados han intentado defender sus potestades tributarias para mantener su interés general fiscal. Esto ha generado, por parte del TJUE, la estructuración de la rule of reason test con la conseguir seleccionar y diferenciar que justificaciones de los Estados puedan ser aceptadas por el Tribunal, ya que ello supone limitar el alcance de los derechos fundamentales europeos.

Todo lo expuesto nos hace pensar que el Tribunal ha desarrollado una especie de teoría sobre el principio de territorialidad y el principio de reparto de potestades tributarias entre Estados o, mejor dicho, ha establecido cuales son los límites extrínsecos a las Libertades de la UE con base en el concepto de «abuso», consiguiendo con ello alcanzar, también, una teoría sobre los límites intrínsecos.

El concepto de abuso que nace del Tratado de Funcionamiento de la UE y de las Directivas europeas busca la consecución del mercado común y que se mantenga en el tiempo, por lo que, este concepto tendrá un carácter finalista. Justificándose con el concepto de abuso, los Estados han estructurado un recurso jurídico para evitar la elusión de su ordenamiento tributario, trasladando a sus normativas internas las normas anti-abuso de las Directivas y del TFUE. Esto ha supuesto que, por parte del Tribunal de Luxemburgo, se establezcan nuevas «contra normas anti-abuso» en base, otra vez, como de un círculo se tratase, a los principios generales de la UE - no discriminación, proporcionalidad, etc.-, a los cuales tiene que adecuarse las medidas anti-abuso nacionales.

En definitiva, la reducción de la carga fiscal mediante la planificación fiscal está avalada por la jurisprudencia europea. Si bien es cierto lo anterior, tenemos que tener claro que el Tribunal de Luxemburgo ha establecido un alto nivel complejidad en la interpretación de sus decisiones, planteando problemas en relación a las alternativas de la planificación fiscal, sobre todo en el ámbito de tributación directa o en la imposición de grupos multinacionales. Es decir, la jurisprudencia del TJUE influirá de diferente manera en las elecciones de economía de opción, ya que al establecer los límites de estas economías harán que determinadas prácticas sean más frecuentes a nivel europeo o, por el contrario, las harán menos frecuentes al ser menos ventajosas.

30 Entre las otras sentencias, véase por ejemplo la de 13 de marzo de 2007, Asunto C-524/04, Test Claimants in the Thin Cap Group Litigation, apartados 106 a 127. 


\section{EL AVANCE NORMATIVO DE LA CONTABILIDAD EN LAS OPERACIONES VINCULADAS}

Cuando hablamos de riesgos fiscales se debe enfatizar en la identificación de los mismos. Función realizada por la auditoría externa, en su labor de desvelar las debilidades significativas del sistema de control interno. En este sentido, con la Norma Internacional de Auditoría (NIA) 700 Formación de la Opinión y Emisión del Informe de Auditoría sobre los Estados Financieros, al establecer que «[d]ebe tenerse en cuenta que la responsabilidad del auditor con respecto al informe de gestión consiste en comprobar y opinar si la información contable contenida en el mismo concuerda con los datos contables de la entidad que han servido de base para preparar las cuentas anuales auditadas. El auditor no tiene obligación de realizar procedimientos de auditoría adicionales para verificar información distinta de la obtenida a partir de los registros contables de la entidad. No obstante, al analizar con el citado alcance el contenido del informe de gestión el auditor considerará si pudiera existir alguna contradicción entre la información económico-financiera del informe de gestión y la contenida en las cuentas anuales».

En otras palabras, nos dice que en el informe del auditor se incluirá un apartado dónde se concluya sobre la concordancia entre la información contable que se describe en el informe de gobierno corporativo y las cuentas anuales. Esta mención deberá ser expuesta en un párrafo con las contradicciones o errores significativos observados en ambos documentos.

Para Rodríguez Rodríguez, lo anterior podría hacernos afirmar «que el auditor no debería poder concluir de forma razonable sobre el adecuado sistema de control interno sobre los riesgos fiscales y del buen gobierno fiscal que ha pretendido afirmar el consejo de administración en relación a su responsabilidad en la toma de decisiones sobre las estrategias fiscales de la empresa, si no se corresponde con una información relevante y fiable que permita concluir que dichas operaciones responden a la sustancia económica de las mismas y no a una mera apariencia legal» ${ }^{31}$.

Aunque lo cierto es que, en el trabajo de verificación del auditor, éste debe ser escéptico con la documentación que le aportan las sociedades en referencia a las operaciones vinculadas entre empresas del mismo grupo, ya que estas operaciones pueden plantear riesgos significativos de errores materiales al diferir la realidad o la sustancia económica en la forma jurídica empleada.

Una forma de detectar estos errores materiales será que dichas transacciones se encuentren fuera del curso normal del negocio, que puedan parecer inusual debido al momento en las que se reflejan, que el importe o naturaleza de las actividades -de las operaciones vinculadas- generen una información contable fraudulenta.

Desde la perspectiva de la contabilidad internacional, la FASB Interpretation No. 48 Accounting for Uncertainty in Income Taxes. An interpretation of FASB Statement No. 109 , es de gran relevancia, puesto que la contabilidad debe reconocer y valorar los riesgos que comportan las estrategias fiscales agresivas mantenidas por la empresa. Según aquella se debe informar de forma separada, aunque tradicionalmente se ha ido informan-

31 RODRÍGUEZ RODRÍGUEZ, A.M. "La contabilidad sobre las estrategias fiscales de las operaciones del grupo ¿Un marco de información para la fiscalidad?”, Documentos-IEF, núm. 15, 2016, pág. 126. 
do de las diferencias entre el gasto por el impuesto sobre sociedades y la cuota a pagar, mediante el impuesto diferido. Este tratamiento contable diferenciado permite superar los problemas que genera el tratamiento habitual de las diferencias contables y fiscales, a través del impuesto diferido. En este sentido, Hanlon Maydew y Saavedra afirman que «no es posible diferenciar cuando tales activos y pasivos por impuestos diferidos se deben a una estrategia contable agresiva que persigue el reconocimiento de ingresos, de aquéllas que buscan la minoración o diferimiento de la carga tributaria» ${ }^{32}$.

\section{LA INCIDENCIA DE LA CONTABILIDAD EN LA FISCALIDAD}

Los órganos de gobierno de las organizaciones empresariales, cuando analizan determinadas inversiones incorporan la carga tributaria como beneficio a conseguir o un coste a reducir. Es decir, incorporan, como opción real, la optimización de la carga tributaria en su estrategia de rentabilidad. Para conseguir el éxito en esta estrategia se basarán en el soporte contable, utilizando tax shelters para conseguir una diferenciación entre las declaraciones tributarias y los libros contables, consiguiendo una disparidad entre los ingresos y gastos fiscales imputables y la contabilidad ${ }^{33}$.

Ello supone la minimización de la carga tributaria, por parte de los contribuyentes, como elemento de la estrategia de rentabilidad. En este sentido, a Rosembuj le resultó revelador el informe de la comisión de investigación sobre imposición del Congreso de los Estados Unidos en el «Caso ENRON». En dicho informe se hace referencia a que la compañía diseñó un departamento fiscal para construir una serie de operaciones con el fin de incrementar los ingresos financieros mediante el ahorro de la carga tributaria o de obtener créditos fiscales de las distintas administraciones tributarias. Este departamento tenía establecidos objetivos, como si se tratase de otra unidad de negocio más, de generar ingresos, todos ellos obtenidos en base a los Estados donde estuviese presente la compañía ${ }^{34}$.

En nuestra opinión, los contribuyentes y sus intenciones sobre la carga tributaria será considerarla como un elemento financiero que genera beneficios o como un elemento de coste a reducir para mejorar la rentabilidad, aplicando para ello las normativas existentes en los Estados donde estén presentes. A modo de ejemplo, si se comparase dos sociedades con idéntico beneficio contable, pero, una paga un gravamen menor que la otra, se podría deducir que existe una planificación en la primera sociedad. Dicha planificación

32 HANLON, H.; MAYDEW, E.L.; SAAVEDRA, D. "The Taxman Cometh: Does Tax Uncertainty Affect Corporate Cash Holdings?” Review of Accounting Studies, 22, 3, 2017, 1202.

33 Según ROSEMBUJ, el tax shelter, en sentido más estricto, es aquella operación, plan, acuerdo o esquema que se diseña para intentar que se anule, reduzca, o se difiera el pago de un impuesto. Se puede realizar mediante informes de expertos, borradores de contratos u opiniones técnicas, justificando pérdidas fiscales, la existencia de créditos fiscales, empleando híbridos financieros para generar dobles deducciones, incluso se puede emplear métodos más complejos como la utilización de sucursales o filiales para conseguir el desplazamiento de la base imponible hacia territorios con mejor clima fiscal o, mediante, el empleo de entidades hibridas para recalificar rentas entre Estados. (Principios Globales de Fiscalidad Internacional, Editorial El Fisco, Barcelona, 2012, pág. 125).

34 Véase el documento de U.S.A. Congress del Joint Committee on Taxation, número 108, de Febrero 2003, titulado "Report on investigation of Enron Corporation and related entities regarding federal tax and compensation issues. Policy recommendations". 
nacerá del establecimiento de procedimientos dirigidos a obtener una reducción en el pago de dichos impuestos, es decir, el tipo efectivo de ambas empresas serán diferentes, aunque el nominal sea idéntico para ambas.

Por lo anterior, Rosembuj determina que la elusión fiscal afectará sobre el tipo efectivo de dos formas. En primer lugar, generando distorsiones entre la contabilidad y el impuesto sobre el ingreso gravable. Y, en segundo lugar, con más desarrollo práctico la obtención de una disminución del tipo efectivo al desplazar ingresos gravables hacia territorios con una tributación más baja ${ }^{35}$. Esta última forma se articulará a través de la utilización de los Special Purpose Vehicle $(S P V)^{36}$, consistente en obtener una reducción de la imposición generando pérdidas en el seno grupo fiscal -empresa multinacional-, a través de un alto grado de endeudamiento -elemento que las caracteriza-, que, a su vez, genera un importante gasto deducible en intereses ${ }^{37}$.

Cuando hablamos de elevar los beneficios contables, sin que ello suponga una mayor base imponible del impuesto, supondrá articular las operaciones a través de entidades híbridas. Un ejemplo de ello sería cuando un contribuyente intentará generar un ingreso exento -no gravable- en una jurisdicción mientras que en la otra jurisdicción será un mero ingreso financiero no sujeto, es decir, obtendrán una disminución del gravamen mediante una diferenciación entre el resultado financiero contable y el resultado fiscal, porque la carga fiscal de la empresa está condicionada por un análisis exhaustivo del ordenamiento tributario. Esto es consecuencia de una planificación fiscal, que intenta beneficiarse de las diferencias contables-financieras en pro de mejorar la rentabilidad de la corporación.

Dicho de otro modo, los contribuyentes internacionales van a buscar un bajo tipo efectivo mediante la optimización en la carga tributaria. Adicionalmente, desde el punto de vista contable, dichos contribuyentes presentarán un efecto secundario, puesto que aumentarán los beneficios financieros no sujetos. Esto puede ser así, concretamente en el plano internacional, al emplearse partes fiscalmente diferentes -a través de entidades híbridas en el extranjero o entidades exentas- que absorberán aquella renta gravable ofre-

35 De forma resumida ROSEMBUJ afirma de que se trata de la minimización del impuesto de manera objetiva para producir de forma deliberada e intencional la elusión de la ley. (Principios Globales de..., cit., pág. 125).

36 ROSEMBUJ define al Special Purpose Vehicle (SPV) como un vehículo jurídico creado por una sociedad, a la que se le denominara sponsor -normalmente estos sponsors serán bancos, tanto tradicionales como de inversión, aseguradoras o filiales de los grupos multinacionales con actividad financiera-, y se caracterizan por carecer de actividad económica y de personalidad jurídica, pudiendo ser sociedades -los ejemplos más claros de SPV son los trust o partnership-. Otro elemento importante es que están radicados en territorios offshore o de baja fiscalidad. El objeto principal de este vehículo es utilizarlo para compra de activos o pasivos, incluso financiar dicha compra por parte de otra entidad del grupo empresarial. Estos vehículos tienen su origen en los concursos de acreedores, ya que se utilizaban para evitar los riegos que pudiesen recaer en la sociedad creadora de los SPV, aunque con el paso del tiempo se han desplegado como poderosos mecanismos en el ámbito fiscal, que, con sus emisiones de títulos, han sido fortalecidos por sus sponsors, generando importantes flujos de renta, con altas rentabilidades y una elevada opacidad. (Principios Globales de..., cit., pág. 126).

37 MILLS, K L.; NEWBERRY, W.; TRAUTMAN, B. "Trends in book-tax income and balance sheet differences", IRS Research Conference, Washington, DC, 2002, págs. 16 y 17. Trabajo recogido en la Conferencia anual sobre investigación, organizada por The Internal Revenue Service de los Estados Unidos de América. 
ciendo una contraprestación a otra entidad presente en otra jurisdicción que tampoco será gravada.

No es casual, por tanto, la afirmación de que la globalización afecta a la toma de decisión de las empresas, buscando como incrementar los recursos financieros de los contribuyentes, sin materializarse en un aumento de coste fiscal. En otras palabras, los contribuyentes internacionales utilizaran las distorsiones existentes entre los distintos sistemas tributarios de los Estados, articulando operaciones que aparenten menguar su capacidad económica y así conseguir una menor tributación. En consecuencia, se tratará del empleo de productos de ingeniería financiera, mediante la estructuración de operaciones financieras que no suponen un riesgo o pérdida en la contabilidad, pero que en el ámbito fiscal van a generar tanto deducciones, exenciones o pérdidas fiscales que harán disminuir la carga tributaria.

Creemos que la herramienta necesaria para corregir estas conductas sería una armonización fiscal ${ }^{38}$, pero ante la falta de ésta, la solución tendrá que articularse mediante la contabilidad y la información pública que se desprende de ésta, para que la presión social haga corregir estas conductas legítimas, aunque un tanto faltas de responsabilidad social corporativa o ética.

\section{CONCLUSIONES}

A lo largo de todo nuestro trabajo, hemos observado cómo influye la planificación fiscal sobre los operadores económicos en la localización de sus inversiones. Del mismo modo, hemos podido evidenciar que la actitud de las grandes corporaciones puede alterar las normativas internas de los ordenamientos tributarios en los que operan.

La homogeneización en la que se han sumergido los gobiernos, ha posibilitado que los contribuyentes internacionales puedan acogerse a normativas que reduzcan su carga tributaria. Dicho de otro modo, el establecimiento de criterios únicos, para poder ser interpretados por todos, puede generar la pérdida de nuestra costumbre o identidad como Estado. Todo ello, en el afán de asegurar un desarrollo económico y el aumento del tráfico comercial. En definitiva, creemos que las grandes organizaciones empresariales intentarán interpretar las normativas fiscales mediante articulaciones de operaciones contables que justifiquen la falta de sustancia económica. Sin embargo, determinados organismos o Estados trabajan en generar una acción indirecta de unificar los criterios de publicidad a los mercados. Con ésta se pretende alcanzar una suerte de seguridad jurídica para los agentes económicos y el cumplimiento de las obligaciones tributarias.

Del mismo modo, desde la perspectiva de los ordenamientos fiscales internos se intenta justificar el abuso de dichas normas fiscales, aunque estén basadas en construir montajes puramente artificiales o sin ninguna realidad económica, con el único pretexto de garantizar la recepción de inversiones en el territorio. Adicionalmente, esta circunstancia va unida a la posibilidad de que los contribuyentes internacionales tengan conductas

38 Desde nuestro punto de vista, la armonización fiscal será aquel proceso de aproximación o convergencia de los sistemas fiscales vigentes, siendo, en definitiva, un instrumento que permite alcanzar objetivos comunes en aquellos ordenamientos tributarios de Estados sociales y democráticos de Derecho 
o interpretaciones diferentes que faciliten el aprovecharse de las discordancias existentes entre los ordenamientos jurídicos de los distintos Estados en los que están presentes.

No obstante, el gran problema que observamos es la falta de una armonización fiscal, de forma que los Estados no utilicen la tributación como herramienta para atraer nuevos contribuyentes que generen una actividad económica y, mediante otros tributos, se intente suplir la reducción de recaudación que esta política fiscal supone.

\section{BIBLIOGRAFÍA}

Alonso García, Ma . C. La responsabilidad patrimonial del Estado legislador, Marcial-Pons, Madrid, 1999.

Alonso García, R. La responsabilidad de los Estados miembros por infracción del Derecho comunitario, Civitas, Madrid, 1997.

Alonso García, R. "El juez español y el Derecho comunitario", Consejo General del Poder Judicial, Madrid, 2003.

BeAsLEY, M. "An Empirical Analysis of the Relation between the Board of Director Composition and Financial Statement Fraud", The Accounting Review, vol. 71, núm. 4, 1996.

CALDERón CARRERo, J. M. "La incidencia de la globalización en la configuración del ordenamiento tributario del siglo XXI", Documentos del Instituto de Estudios Fiscales, núm. 20, Madrid, 2006.

Callao Gaston, S.; Gasca Galán, M., y Jarne Jarne, J. I. “Gobierno corporativo e información contable", Revista de Contabilidad, vol. 1, 2008.

Cobreros Mendazona, E. "Incumplimiento del Derecho comunitario y responsabilidad del Estado", Civitas, Madrid, 1994.

Collado Yurrita, M. A. y Patón García, G. "Las Fuentes del Derecho Tributario Internacional", en la obra de CORDÓN EZQUERRO, T. Manual de Fiscalidad Internacional, Vol. I, $3^{\text {a }}$ ed., Instituto de Estudios Fiscales, Madrid, 2007.

Comisión EuropeA, Comunicación del 10 octubre del 2007, COM (2007)785 final, “Aplicación de medidas contra las prácticas abusivas en el ámbito de la fiscalidad directa dentro de la UE y en relación con terceros paises".

Cruz Padial, I. "Globalización Económica: Sinónimo de desnaturalización tributaria", Crónica Tributaria, núm. 109, 2003.

De Arespacochaga, J. Planificación fiscal internacional, Marcial Pons, 2da edición, Madrid, 1998.

DeChow, P.; SloAn, R. y SweEneY, A. "Causes and consequences of earnings misstatement: An analysis of firms subject to enforcement actions by the SEC", Contemporary Accounting Research 13, 1996.

Elvira Benito, O. y Amat Salas, O. "La manipulación contable: tipología y técnicas", Partida Doble, núm. 203, 2008.

Fama, E. F. "Agency Problems and the Theory of the Firm”, vol. 88, núm. 2, 1980.

FAma, E. F. y Jensen, M. C. "Separation of ownership and control", Journal of Law and Economics, 26 (2), 1983.

García De Enterría, E. "La responsabilidad patrimonial de la Administración española por daños causados por infracción del Derecho comunitario", Gaceta Jurídica de la CEE, núm. 60, 1989.

García Novoa, C. "El derecho tributario a las puertas del Siglo XXI. Retos de futuro". Mundo fiscal, Vol. $1,2009$.

García Novoa, C. "El actual contexto internacional y el principio de residencia en las rentas de actividades empresariales", Crónica Tributaria, núm. 165, 2017.

García Rodríguez, J. M. “Tax Shelters y Fraude: Detección y Control de la Planificación Fiscal. Abusiva. Análisis de la experiencia Estadounidense", Crónica Tributaria, Núm. 140, 2011. 
Gutiérrez Lousa, M. y Rodríguez Ondarza, J. A. "Las consecuencias fiscales de la globalización", Documentos del Instituto de Estudios Fiscales, núm. 8, Madrid, 2007.

Jensen, M. C. y MecKLing, W. H. "Theory of the firm. Managerial behavior, agency costs and ownership structure", Journal of financial Economics, 3(4), 1976.

Hanlon, H.; Maydew, E. L. and SaAvedra, D. "The Taxman Cometh: Does Tax Uncertainty Affect Corporate Cash Holdings?” Review of Accounting Studies,22, 3, 2017.

Mangas Martín, A. y Liñán Nogueras, D. J. Instituciones y Derecho de la Unión Europea, Tecnos, Madrid, $6^{\mathrm{a}}$ ed., 2010.

Martínez JimÉNEZ, F. J. "La incidencia contable en la fiscalidad: ¿Hacía una reducción de la carga tributaria?, en la obra colectiva V.V.A.A. Actas del XIX Encuentro Internacional AECA-Guarda 2020, AECA, Madrid, 2020.

Mills, K. L.; Newberry, W. and Trautman, B. "Trends in book-tax income and balance sheet differences", IRS Research Conference, Washington, DC, 2002.

Nash, J. F. "Equilibrium Points in n-Person Games," Proceedings of the National Academy of Sciences, Vol. 36, 1950.

OECD. Informe de 1998, titulado "Harmful Tax Competition: an Emerging Global Issue”, OECD, Paris.

RodríGUEz RodríGUEZ, A. M. "La contabilidad sobre las estrategias fiscales de las operaciones del grupo ¿Un marco de información para la fiscalidad?", Documentos del Instituto de Estudios Fiscales, Núm. 15, 2016.

Rivero ToRRe, P. "Responsabilidad Social Y Gobierno Corporativo: Información Y Transparencia”, Revista Asturiana de Economía, 2005

Rusembuj, T. Principios Globales de Fiscalidad Internacional, Editorial El Fisco, Barcelona, 2012.

Stiglitz, J. E. "The General Theory of Tax Avoidance", National Tax Journal, Columbia University Academic Commons, Vol. 38, 1985.

Stiglitz, J. El malestar en la globalización. Punto de lectura, Madrid, 2002

Stolowy, H. And BReton, G. "A framework for the classification of accounts manipulations", Les cahiers de recherche, 708, Chambre de Commerce et d'industrie de Paris, 2000.

TanzI, V. "Globalization, Tax Competition and the Future of Tax Systems", Documento de Trabajo WP/96/141, Fondo Monetario Internacional, 1996.

TANZI, V. "La globalización y las acciones de las termitas fiscales", Finanzas y Desarrollo, Fondo Monetario Internacional, 2001.

U.S.A. Congress del Joint Committee on Taxation, número 108, de Febrero 2003, titulado "Report on investigation of Enron Corporation and related entities regarding federal tax and compensation issues. Policy recommendations". 